\title{
BONE MARROW INVASION BY ASPERGILLUS SPECIE IN A SICKLE CELL TRAIT PATIENT WITH IN V ASIVE ASPERGILLOSIS: A FATAL CASE IN ASSOCIATION WITH DISSEMINATED INTRAVASCULAR COAG ULATION
}

\author{
${ }^{1}$ Farouk AG , ${ }^{1}$ Ibrahim BA, ${ }^{2}$ U mar UH, , ${ }^{3}$ ukar AA, ${ }^{1}$ A mbe JP \\ ${ }^{1}$ Department of Paediatrics, College of Medical Sciences, University of Maiduguri, \\ Maiduguri, Borno State \\ ${ }^{2}$ Department of Radiology, University of Maiduguri Teaching Hospital, Maiduguri, Borno State \\ ${ }^{3}$ Department of Haematology, College of Medical Sciences, University of Maiduguri, Borno State \\ Correspondences and reprint request to: Dr A bubakar G arba Farouk, \\ Department of Paediatrics, University of Maiduguri, College of Medical Sciences, PMB 1069 \\ Maiduguri, Borno State, Nigeria. Email: farouk649@gmail.com Tel: +2348038164110
}

\begin{abstract}
Background: Invasive aspergillosis has been predominantly associated with pulmonary infection, particularly amongst immunocompromised individuals. Extrapulmonary infections with A spergillus specie have been reported rarely irrespective of immune status. Risk factors for invasive aspergillosis include prolonged and severe neutropenia, haematopoietic stem cell and solid organ transplantation, advanced AIDS, and chronic granulomatous disease. The most frequently involved specie is A spergillus fumi gatus that constitutes over $90 \%$ of cases, followed by A spergillus flavus, usually associated with a primary skin infection. Haematogenous spread to the bone causing osteomyelitis is the commonest form of disseminated aspergillosis and a surprisingly high proportion of these patients have no immunosuppression. We present a rare case of bone marrow invasion by Aspergillusspp. in a 3-year-old patient with sicklecell trait and chronic A spergillosis. Case report: A 3-year-old patient with sickle cell trait was brought to the paediatric unit with recurrent diarrhoea, abdominal distention, weight loss and persistent cough. The child was severely wasted with generalised peripheral lymphadenopathy. She had marked respiratory distress and hepatosplenomegaly but no demonstrable ascites. Haematologic examination reveal ed leukaemoid reaction (leukocyte count of $44.0 \times 10^{\circ} / \mathrm{L}$ ) with monocytosis (10\%) and thrombocytopenia (platelet count of 97,000/ $\mathrm{mm}^{3}$ ); no blast cells were seen on blood film. The bonemarrow was hypercellular with a myeloid/ erythroid ratio of 20:1, consistent with infection. BoneM arrow cultureyiel ded A spergillusspp. and other results of sepsis work up were negative. Conclusion: Cases of extrapulmonary invasiveaspergill osishave been reported rarely in both immunocompetent and immunocompromised patients. Haematogenous spread to the boneisthecommonest form of disseminated disease.
\end{abstract}

Keywords: Bone marrow, Chronic, Invasive aspergillosis, Sickle cell trait.

\section{INTRODUCTION}

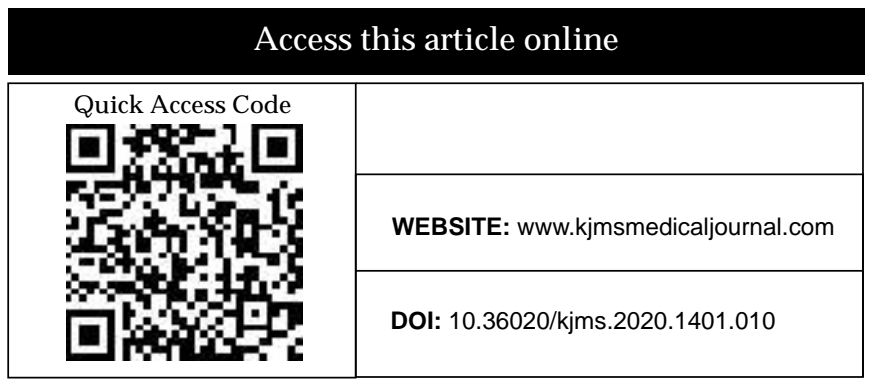

Invasive Aspergillosis (IA) is an opportunistic fungal infection that is commoner in immunocompromised than immunocompetent individuals. It is acquired through inhalation of aerosolized spores. Invasive Aspergillosis is associated with higher morbidity and mortality in the setting of severe immunosuppression. Risk factors for IA include prolonged and severe 
neutropenia, haematopoietic stem cell and solid organ transplantation, advanced AIDS, and chronic granulomatous disease. Infection with the fungus affects the respiratory tract in about $90 \%$ of cases. ${ }^{1}$ Invasive aspergillosis most commonly involves the sino-pulmonary tract reflecting inhalation as the principal portal of entry. In the respiratory mucosa, inhaled spores germinate into hyphae, which invade the mucosa and lead to invasive pulmonary Aspergillosis(IPA). ${ }^{2}$

Over the approximately 185 different Aspergillus species identified, only a small percentage cause human disease. ${ }^{3}$ The most frequently involved specie is A. fumigatus that constitutes over $90 \%$ of cases followed by A. flavus which usually cause primary skin infection. ${ }^{4,5}$ Less-frequent causes include A.niger, A.terreus and A.ustus. ${ }^{6,7}$ A study from the US reported that IA in children with compromised immunity was associated with prolonged hospital stay and increased total hospital charges compared with immunocompromised children withoutIA. ${ }^{8}$

Aspergillus species may colonise the skin to cause cutaneous infection and more rarely enter the body via the gut to cause gastrointestinal infection. Haematogenous dissemination is the commonest mode of spread to the bone causing osteomyelitis. ${ }^{4}$ Other rarer sites of the disseminated disease include the central nervous system, cardiovascular system and other organs. ${ }^{4,9}$ We hereby report a rare case of marrow invasion by aspergillus species in a 3-year-old patient with sickle cell trait and disseminated aspergillosis.

\section{CASE REPORT}

A 3-year-old girl was referred to the Specialist Paediatric Haemato-oncology unit from thegeneral Paediatric outpatient dinic of the University of Maiduguri Teaching Hospital (UMTH) with 6 months history of recurrent diarrhoea, initially, blood-stained. The subsequent episodes were nonbloody, with a frequency of 4 to 5 times per day, each episodelasting 1 to 2 weeks and was diarrhoea free for 1 to 2 weeks, small in quantity, non-mucoid and no passage of worms. Three months after the onset of diarrhoea she was noticed to be progressively losing weight evident by the loosening of previously fitted clothes and appearancebony prominences. Two months before presentation she developed abdominal distension insidious in onset, progressively increasing but occasionally subsides following the passage of loose stool, there was associated abdominal pain which was poorly described that subsided 3 weeks before presentation. There was no vomiting, no yellowness of the eyes and no refusal to feed. One month later she developed a non-paroxysmal cough, non-barking and no associated difficulty in breathing. There was no history of established contact with adult having chronic cough, no history of ingestion of unpasteurised milk, she has had BCG vaccination with an evident scar. Therewasno history of fever. She had never been transfused. However, she has a sibling with sicklecell anaemia, but no history of sibling death or recurrent pregnancy loss of her mother. There was no family history of malignancy, no exposure to ionizing radiations, and no history of travels.

Physical examination revealed a child in respiratory distress with marked wasting. Vitals signs at presentation revealed an axillary temperature of $37.0^{\circ} \mathrm{C}$, respiratory rate of 50 cycles/min, pulse rate of 90 beats/ min, blood pressure was $90 / 60 \mathrm{mmHg}$, oxygen saturation at room air was $92 \%$, and $98 \%$ on oxygen via the intranasal route. The patient was pale with significant generalised peripheral lymphadenopathy, but not jaundiced, not dehydrated. Thelymph nodes in thecervical region were firm, matted, non-tender, and no other features of acute inflammation with the largest measuring $1 \times 0.5 \mathrm{~cm}$. However, no lymph node biopsy was done as caregiver effuse to give consent.There was no discharging sinuses and no pedal oedema. She weighed $10.5 \mathrm{~kg}$ ( $75 \%$ of the expected for her age), height was $86 \mathrm{~cm}(90.5 \%)$, mid-upper arm circumference (MUAC) of $11 \mathrm{~cm}$ (severely malnourished).

She was in respiratory distress with widespread broncho-vesicular breath sounds, no adventitious sounds. The abdomen was grossly distended (abdominal girth: $69 \mathrm{~cm}$ ) with hepatomegaly of $10 \mathrm{~cm}$ below the right sub-costal margin at the midclavicular lineand a liver span of $14 \mathrm{~cm}$, theliver was smooth, firm, and non-tender. There was firm, 
smooth and non-tender splenomegaly of $9 \mathrm{~cm}$. There was no demonstrable ascites and bowel sounds werenormo-active. Examination of systems did not reveal any abnormalities.

Haematologic examination revealed a Haemoglobin concentration of $11 \mathrm{~g} / \mathrm{dl}$, Total Leucocyte Count (TLC) of $44 \times 10^{\circ} / \mathrm{L}$ (Leukaemoid reaction) (normal range: $3-10 \times 10^{\circ} / \mathrm{L}$ ), with neutrophils constituting $43 \%$, lymphocytes $47 \%$, and monocytes of $10 \%$, and thrombocytopenia with a platelet count of $97,000 / \mathrm{mm}^{3}$ (normal range: $\left.100,000-450,000 / \mathrm{mm}^{3}\right)$. The blood film did not reveal any blasts. Bonemarrow aspiration revealed hypercellularity with a myeloid/ erythroid ratio of 20:1, erythropoiesis of mixed micro-normoblasts and megaloblasts. There was myeloid hyperplasia with sequential maturation consistent with infection of the marrow. Bone marrow culture yielded Aspergillus spp. However, cultures from blood and urine did not yield any growth while baseline tests for kidney and liver functions were essentially normal.

Chest Radiograph showed widespread nodular opacities with patchy shadows in both lung fields worse at the perihilar region and repeated chest radiograph after 2 weeks showed nodular opacities in the perihilar and basal regions which showed minimal resolution of the previously noted lesions (Figure 1). Abdominal ultrasound scan showed peri-porta, peripancreatic and para-aortic lymphadenopathy and also enlarged liver and spleen representing hepatosplenomegaly (Figure 2). Mantoux reaction was $0 \mathrm{~mm}$, early morning gastric washout for acid-fast bacilli was negative. Other basel ine investigations that includeliver and renal function tests, random blood glucose, and urinalysis were unremarkable. Human immunodeficiency virus (HIV) screening was negative.

A diagnosis of IPA with bonemarrow involvement was made. She was commenced on IV voriconazole $6 \mathrm{mg} / \mathrm{kg}$ q12hrly day 1 , then $4 \mathrm{mg} / \mathrm{kg}$ q12hrly for 6 days, then oral voriconazole at $4 \mathrm{mg} / \mathrm{kg}$ q12hrly intended for 12 weeks. Four weeks later into the treatment with voriconazole the patient developed severe jaundice, upper GI bleeding and bleeding from puncture sites suggesting possiblevoriconazoleinduced liver injury and probable association of IA with disseminated intravascular coagulopathy (DIC). The bleeding was controlled following transfusion of fresh whole blood. A repeated LFT revealed derangement with a total bilirubin of $172 \mu \mathrm{mol} / \mathrm{L}$ (normal: 1.7 17.1 $\mu \mathrm{mol} / \mathrm{L}$ ), conj. bilirubin $131 \mu \mathrm{mol} / \mathrm{L}$ (normal: $1.7-8.5 \mu \mathrm{mol} / \mathrm{L}$ ), total protein 63g/ L (normal: 58 $80 \mathrm{~g} / \mathrm{L}$ ), albumin $29 \mathrm{~g} / \mathrm{L}$ (normal: $35-50 \mathrm{~g} / \mathrm{L}$ ), alkaline phosphatase activity of 221liu/ L (normal: 60 - 170iu/ L), ASAT of 24iu/ L (normal: up to 15iu/ L), and ALAT of 16liu/ L (normal: up to 22iu/L). Voriconazole was stopped and Itraconazoleintended to beintroduced.

Five days later, she refused oral feeding and her caregivers declined nasogastric tube feeding. She developed hypoglycaemia (random blood glucose $2.0 \mathrm{mmolL}$ ). A bolus of $10 \%$ dextrose at $200 \mathrm{mg} / \mathrm{kg}$ was given and she was later maintained on $5 \%$ dextrose saline and oxygen therapy was also introduced when oxygen saturation in room air was $92 \%$. Despite the initial improvement, her condition deteriorated. All efforts to resuscitate her failed and the patient died on day 42 of admission. The possible cause of death in our patient is possibly hepatic failurefrom voriconazoleinduced hepatocellular damage and disseminated intravascular coagulopathy. 



Figure 1:(A)Chest Radiograph showing widespread nodular opacities with patchy shadows in both lung fields worse at the perihilar region and $(B)$ repeated chest radiograph after 2 weeks showing nodular opacities in the perihilar and basal regions.

Figure 2: Ultrasound images (A $\& B)$ showing multiple periporta hepatic, and para-aortic regions lymphadenopathy as labelled with the black arrows.

\section{DISCUSSION}

Invasive Aspergillosis (IA) is a rare opportunistic disease seen in immunocompromised patients; it is extremely rare in immunocompetent patients and poses a serious diagnostic challenge. ${ }^{10,11}$ Predisposing factors include leukaemia, use of steroids for chronic pulmonary diseases, other immunosuppressive drugs for the treatment malignancy, and other diseases such as diabetes mellitus, chronic granulomatous disease, or human immunodeficiency virus (HIV) infection all of which our patient did not have. The most common cause of human opportunistic fungal infection after Candida albicans is the Aspergillus species. The organism is in abundance in the environment, and common sources are decaying vegetation, stored grains, and soil. ${ }^{5,6,7,10}$ Development of IA has been rarely described; mostly in adult Haematooncol ogy settings. ${ }^{12-14}$ The diagnosis of aspergillosis is often challenging because the symptoms are usually non-specific and overlap with those of pulmonary tuberculosis (PTB) and therefore most often delayed due to lack of clinical suspicion in patients without classic risk factors. Nigeria is ranked 6th among the 30 high TB burden countries in theworld and 1st in Africa. Nigeriaal so accounts for $8 \%$ of the global gap between TB incidence and notified cases. ${ }^{15} \mathrm{~N}$ igeria contributes $9 \%$ to the global 3.6 million missing TB cases after India and Indonesia with $26 \%$ and $11 \%$ respectively. An estimated 418,000 new TB cases in N igeria in 2018 and the country notified 104,904 (25\%) and 106,533 cases of TB in 2017 and 2018 respectively giving a gap of 314,712 and 319,599 cases yet to be notified respectively. ${ }^{16}$ This implies that a large number of TB cases are still undetected/missing thereby constituting a pool for continuous transmission of the diseasein the community. Themissing TB cases in Nigeria can be found among men, women and children with different forms of TB, including drugresistant TB. The proportion of missing TB cases among children is more worrisome, as Nigeria was only ableto notify $7 \%$ of theestimated childhood TB cases in $2017 .{ }^{16}$ Withthe isolation of A spergillus spp. 
from the bone marrow, the diagnosis of IPA was highly possible; hence, a decision to treat with voriconazole, which is inconsistent with the recommendations from the 2016 updated clinical practice guidelines of the Infectious Diseases Society of A merica (IDSA). ${ }^{17}$ In this situation where wehad to use voriconazole, the serum level needed to be monitored; unfortunately, this is not available in our facility. Aspergillusinfection in settings other than a haematopoietic stem cell and solid organ transplantation, prolonged and severe neutropenia, advanced AIDS, and chronic granulomatous disease, the patient may presents with symptoms progressing over several weeks to months, which was thecasewith our patient. ${ }^{1820}$ The acute form of invasive and disseminated aspergillosisis considerably morecommon than the chronic form and seen mainly in patients with diabetes mellitus, human immunodeficiency virus (HIV) infection or chronic granulomatous disease or those who have received corticosteroids for chronic obstructive air way disease; none of these was present in our patient. The usual symptoms of chronic aspergillosis in children are chronic cough, low-gradefever, weight loss and malaise for which the case reported presented with all. Even though, our patient did not haveconsistent clinical features suggestive of immunosuppression, the findings of massive hepatosplenomegaly, chronic cough and fever, led to her hospitalization and a work up for possible differential diagnoses. Unlike the invasive form, chronic aspergillosis occurs in immunocompetent patients. ${ }^{1.212}$ Chronic pulmonary aspergillosis has al so been reported to be the most subtle, yet severelong-term complication of chronic pulmonary infection than is generally appreciated. ${ }^{22}$ There is considerable overlap in symptomatology between PTB and chronic pulmonary aspergillosis in children with chronic cough, fever, weight loss, fatigue and dyspnoea being commonfeatures.

The mortality rate of IA remains high, especially in resource-poor settings like ours and particularly in patients with $\mathrm{DIC}^{23}$ Presence of DIC in patients with IPA was associated with $93 \%$ death in Lai et al series, $^{23}$ and mortality rate exceed $50 \%$ in neutropenic patients, ${ }^{24}$ and $90 \%$ in stem cell transplantrecipients. ${ }^{25}$

\section{CONCLUSION}

Invasive aspergillosis and pulmonary tuberculosis can coexist in an immunocompetent child with considerable overlap in the clinical presentation of these chronic pulmonary infections hence the need for a high index of suspicion. Therapeutic approach should be evaluated case by case taking into account thelikelihood of drug-drug interactions.

\section{REFEREN CES}

1. Meyer RD, Rosen P, Armstrong D, Yu B. Aspergill osis complicating neoplastic disease. AmJ Med 1973, 54: 6-15

2. Zmeili OS, Soubani AO. Pulmonary Aspergillosis: A clinical update. QJM. 2007; 100(6): 317-34

3. Krishnan S, Manavathu EK, Chandrasekhar $\mathrm{PH}$. Aspergillus flavus: an emerging nonfumigatus Aspergillus species of significance. Mycoses 2009; 52: 206-22

4. Paterson DL. N ew dinical presentations of invasive Aspergillosis in non-conventional hosts. EurJ Clin Microbiol InfectDis 2004; 10: 24-30

5. Romano C, Miracco C. Primary Cutaneous Aspergillosis in an immune-competent patient. Mycoses 2003; 46: 56-9

6. Ozer B, Kalaci A, Duran N, Dogramaci Y,
Yanay AN. Cutaneous infection caused by aspergillus terreus: A Case report. J Med Micro 2009; 58: 968-70

7. Granstein RD, First LR, Sober AJ. Primary cutaneous aspergillosisin a prematureneonate. $\mathrm{Br}$ J Dermatol 1980; 103: 681-4

8. Zaoutis TE, Heydon $\mathrm{K}, \mathrm{Chu} \mathrm{JH}$, et al. Epidemiology, outcomes, and costs of invasive aspergillosis in immunocompromised children in theUnited States, 2000. Pediatrics 2006; 117: e711-16 9. Doris J, losifidis E. Central nervous system aspergillosis in children: a systemic review of reported cases. Int] Infect Dis 2007; 11: 381-93

10. Ajith C, Dogra S, Radotra BD, Chakrabarti A, Kumar B. Primary Cutaneous A spergillosisin an immunocompetent individual. J Eur Acad Dermatol Ven 2006; 20: 738-739

11. Tahir C, Garbati M, Nggada HA, Terna 
Yawe EH, Abubakar AM. Primary Cutaneous Aspergillosis in an immunocompetent patient. Journal of Surgical Techniqueand case report 2011; 3(2): 94-96

12. Buonomo AR, Viceconte G, Compare D et al. Invasive pulmonary aspergillosis and pulmonary tuberculosis in a patient treated with infliximab for Chron's disease. IDCases https:/ / doi.org/ 10.1016/ j.idcr.2019.e00537

13. van der Klooster JM, Bosman RJ, Oudemans-van Straaten HM, van der Spoel JI, Wester JPJ, Zandstra DF. Disseminated tuberculosis, pulmonary aspergillosis and cutaneous herpes simplex infection in a patient with infliximab and methotrexate. Intensive Care Med 2003; 2327-9

14. Xu Y, Zhau Y, Liu Y et al. Case report a rare case of synchronous mycobacterium tuberculosis, aspergillosis and lung adenocarcinoma in a patient [Internet]. Int J Clin Exp Pathol 2016; 9: Available fromwww.ijcep.com

15. Jannamike L. "302,096 tuberculosis undetected in Nigeria - NTBLCP", March 15 2018, $\begin{array}{lllllllll}V & a & n & g & u & a & r & d\end{array}$ https:/ / www.vanguardngr.com/ 2018/ 03/ 302096 -tuberculosis-cases-undetected-nigeria-ntblcp/

16. Emorinken M. Nigeria to expand the diagnosis and treatment of TB. Published: March $20 \mathrm{th} \quad 2020 . \quad A v a \mathrm{ilable}$ fromwww.tbonline.info/ posts/ 2019/3/ 20/ nigeri a-expand-diagnosis-and-treatment-tb/

17. Patterson TF, Thompson GR, Denning DW, et al. Practice guidelines for the diagnosis and management of aspergillosis: 2016 update by the infectious diseases' society of America. Clin Infect Dis2016

18. Kato $\mathrm{T}$, Usami I, Morita $\mathrm{H}$ et al.Chronic necrotizing pulmonary aspergillosis in pneumoconiosis: clinical and radiological findings in 10 patients. Chest 2002; 121: 118-27

19. Denning DW. Chronic forms of pulmonary aspergillosis. Clin Microbiol infect 2001; 7 (suppl.

2): 25-31

20. Wong PC, Fung SL, Lee J, Wong CF, Chau $\mathrm{CH}$, Yew WW. Chronic necrotizing pulmonary aspergillosis. A report of ninecases with analysis of clinical picture, risk factors and treatment for outcome correlation. Monaldi A rch Chest Dis 2001; $56: 202-7$

21. Restrepo BI. The convergence of tuberculosisand diabetes epidemics: renewal of old acquaintances. Clin. Infect. Dis. 2007; 45: 436-438

22. Ekwueme $C$, Otu $A A$, Chinenye $S$ et al. Haemoptysis in a female with diabetes mellitus: a unique presentation of chronic pulmonary aspergillosis, pulmonary tuberculosis, and Klebsiella pneumoniae co-infection. Clinical Case Reports 2016; 4(4): 432-436

23. Lai Chih-Cheng, Liaw Shwu-Jen, LeeLi-Na, Hsiao Cheng-Hsiang, Yu Chong-Jen, Hsueh PoRen. Invasive pulmonary aspergillosis: high incidence of disseminated intravascular coagulation in fatal cases. J Microbiol Immunol Infect. 2007; 40: 141-147

24. Yeghen T, Kibbler CC, Prentice HG et al. Management of invasive pulmonary aspergillosis in haematology patients: A review of 87 consecutive cases at a single institution. Clin Infect Dis. 2003; 31(4): 859-68

25. Fukuda T, Boeckh M, Carter RA et al.Risk and outcome of invasive fungal infections in recipients of allogeneic hematopoietic stem cell transplants after nonmyeloblative conditioning. Blood. 2003; 102(3): 827-33

Cite this article as: Farouk AG, Ibrahim BA, Umar UH, Bukar AA, A mbeJP Bone Marrow Invasion by A spergillus Specie In a Sickle Cell Trait Patient With Invasive Aspergillosis: A Fatal Case In A ssociation With Disseminated Intravascular Coagulation. KJMS 2020; 14(1): 72 - 77. 